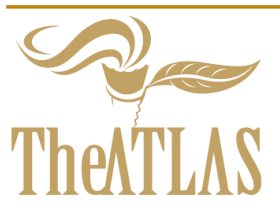

\title{
Philosophy of Transdisciplinarity: Approaches to the Definition
}

Larisa Kiyashchenko, Doctor of philosophical Sciences, leading researcher Institute of philosophy Russian Academy of Sciences, Email:Iarisakiyashchenko@gmail.com

Received 27 June 2017; Revised 19 July 2017; Accepted 20 July 2017

Copyright (C) 2017 Larisa Kiyashchenko. This is an open access article distributed under the Creative Commons Attribution License (https://creativecommons.org/licenses/by/4.0/), which permits unrestricted use, distribution, and reproduction in any medium, provided the original work is properly cited.

Available online 27 August 2017 at www.atlas-journal.org, doi: 10.22545/2017/00084

\section{T}

he article shows that the experience of practical philosophizing is the cornerstone of the possibility to define the philosophy of transdisciplinarity. The conditions for this experience are an active and motivated participation in the solution of actual existential problems connected with the existence of objects proportional to the person. Along with traditional forms of disciplinary scientific knowledge (natural and social sciences), a wide range of daily practical knowledge, religious and other experiences are involved in the production of knowledge required for dealing with these problems. The article notes that, owing to boundary nature of transdisciplinary experience, its conditions both precede the experience as an accumulated knowledge, and at the same time are newly redefined and become others (are in a sense generated) depending on concrete circumstances of the experience. The result of such interaction is a paradoxical development of practical activities whose "aposteriority-aprioristic" forms combine a variety of universal definition of what is disciplinary and generally valid by agreement of daily, practical knowledge. Owing to the above, the philosophy of transdisciplinarity has, among other features, an incomplete, procedural nature of "open work" (U. Eko), and the style of philosophizing is developed in three main transpositions (the observer, the participant, the witness).

Keywords: Transdisciplinarity philosophy, practical experience, casus, reflection, transposition concept.

\section{Introduction}

We are going to use the term "transdisciplinarity" in contrast to the term "interdisciplinary" for defining such cognitive situations in which, for various reasons (which we are going to discuss below), the scientific mind (both in the science and philosophy) is compelled to search for integrity and its own validity (in order to clarify the conditions of possible experience) and make a transcending shift to the sphere bordering on the life-world.

Powerful impulses coming from the purely practical sphere are prerequisites for this shift. This is a need for development of a problem-oriented re- 
search aimed at finding solutions of current practical problems such as those in the field of environment, energy, information, demography, health problems, etc. As a result a new type of research activity generating scientific knowledge is formed. In sociology and philosophy of science it is being researched under the name of "postnonclassical science" (V.S. Styopin), "type 2 science" (Gibbons M., Nowotny H.), postacademic science (Ziman, J), science of 'another Art Nouveau' (U. Beck), et al. The modern type of scientific knowledge generating is a hybrid of fundamental research oriented towards cognition of some true state of affairs and the research pragmatically oriented towards achieving some useful effect. For example, discovery of genes or stem cells is followed by their patenting which requires description of their useful properties. It is no coincidence that this type of scientific activities is highly commercialized. Its execution is carried out in a complex network of academic, commercial, government, and non-government public institutions. In the classical type of knowledge generation the value system exists in a somewhat implicit way (like Merton ethos of science) and is controlled by the system of intrascientific mechanisms. In the new type (which is expressed mostly in biology and medicine) a reflection arises for this system of values which is implemented through these very transdisciplinary mechanisms of normative registration of scientific practices (institutionalized both within and beyond science). In these transdisciplinary mechanisms representatives of humanitarian disciplines (especially, philosophers) and public members are playing an active role. It is important to emphasize that transdisciplinarity has proven to be one of the vectors of the multidimensional transgression of modern science beyond its classical identity. Precisely in this respect it shows up as a matter of philosophical discussion.

However, science does not cease to be science and philosophy is not changed into 'philodoxy' (I. Kant). Philosophy's advancement to the limits of the lifeworld turns out to be a result of search of its own grounding, realization of the need in justification and consistency of its own judgments. The science moving in the same direction gets a chance to preserve the integrity of world perception which it inevitably loses in the increasing disciplinary fragmentation. At this, philosophy and science entry a special border regime of its existence, adapting to the experience of the limit [1]. From our point of view learning the transdisciplinary experience makes it possible to reveal a positive sense of the crisis phenomenon of the scientific mind self-identity (of science and of philosophy as the science of sciences). This crisis frightened and continues to frighten some researchers with potential negative consequences endangering modern culture in general. It caught and continues to catch magnetic interest of others.

At the same time it has a positive value in terms of defining the individual features of each knowledge type as a result of meeting with other. Meetings of science and philosophy which happened many times at the breaking moments of their historical development are examples of it. For us the pivotal fact is that the next meeting of the disciplinary scientific knowledge with philosophy and of philosophy with scientific knowledge is actually happening here and now on the borders with the life-world, defining the specifics of the phenomenon which we call transdisciplinarity. In order to characterize the specificity of this "here and now" we have used another term that needs to be clarified - the term of "bioethics" casus.

We borrow the term "casus" from the civil law tradition (the most typical example is the United States) where precedents (casus or cases) play the regulatory role. The court decisions on private legal conflicts act as standards for evaluation and decisionmaking in other situations [2]. The single thereby turns to be a source of the common. In this sense, the "casus" is fundamentally different from the "example" indicating application of a general rule to a particular case or granting empirical concepts reality in contemplation (I. Kant).

In the context of our application the casus can be defined as a specific case or a life episode which provokes a variety of disciplinary and extradisciplinary responses (responsibility) and at the same time ties them into some joint effect acting as some common reason (leash). Next, and this is already assumed in the above, the casus provides some space of opportunities for these answers, their "possibility" (V.S. Bibler), or "virtuality" (G. Deleuze), yet again, not in the form of intelligible basis, but as a real event in the life-world of the man. Moreover, the sphere of possibilities includes specific circumstances of the case, and its position (place) in the social-cultural context. Therefore, generally the casus shall be understood as a ground-breaking event provoking search for specific grounds, justification, and consistency of philosophical and scientific discourses in 
transdisciplinary practices.

Of course, not every incident can become a casus. It is essential that the life incident has a momentum provoking a need for comprehension, for advancing beyond the limits of the ordinary, popular belief ("doxa"). A life incident must be paradoxical. It must contain a mandatory requirement for scientific, philosophical, theological and other disciplinary understanding, i.e., nomination beyond the life-world in search of a theoretically grounded idea of truth or benefit which could aspire to the status of universal. If we try to schematize it, we can say that the universality embodies integrity of sense and drawing the subject into itself as a problem of identifying the connection of the single with something radically other [3]. For this to happen the casus should have the quality of tragic 'aporia' or 'amechania': "This is impossibility to act in conditions of necessity to act. It originates not from a consciousness of the world's "upset", yet, in clear opposition and confrontation of equally powerful and equally right forces or needs ..." "Plunging into this aporia, the energy ... of actions is converted into the energy of thought, or rather, into the energy of consciousness" [4].

Existential energy of the life incident aporia is executed in the variety of scientifically, philosophically, theologically and disciplinarily justified decisions. Yet, the complexity of existential problems (bioethics, ecology, or energy) is that no disciplinary justifications at any necessity can claim to be sufficient. Truth faces truth, goodness faces goodness, veritas faces veritas causing aporia of mind and generating a paradoxical impetus for seeking the grounds and consistency, yet now in the sphere of transdisciplinary communications of the life-world - in the sphere of universal significance. The universal significance expresses a social convention and is based on the object composition of a joint action of a group.

It is only the presence of this double, oppositely directed, localized on the boundaries of disciplinary and life-worlds impetus of paradoxality that turns an incident into a transdisciplinarity casus. Thus, the phenomenon of disciplinarity clearly demonstrates the dual nature of our idea of universality and fundamentality of the life-world in which the diversity of human activities unfold. The universe and the integrity of the human presence in the world are based on the mobility of the "tectonic plates" of universality and general validity, which form it unitedly and distinctly.
Once again we emphasize that the variety of casus in bioethics, which concern both the scientific community and public opinion, makes bioethics itself a casus in the above mentioned sense. It is in this sense that we consider the casus of "bioethics", i.e. as a kind of a specific event being an impetus for the emergence of philosophy of transdisciplinarity, and not just as a form of application of "fundamental" philosophical (anthropological, ethical, etc.), biological, medical, and other disciplinary knowledge to specific situations in the biomedical science and practice. The traditional 'paternalistic' opposition of fundamental and applied knowledge is counterproductive in this case.

Initially bioethics was formed as a transdisciplinary approach to understanding and finding answers to complex moral and anthropological problems arising from the development of biomedical technologies (sometimes literally - on the verge of life and death). At the same time from the very beginning a fundamentally important pre-understanding (yet, not based on any theoretical concepts) has practically developed, according to which:

1. The question of what is the benefit of patient, or the good of society in situations generated by advances in biomedical technologies, can not be solved exclusively based on an expert opinion of natural scientists. The interdisciplinary cooperation with representatives of the humanities (especially philosophy) is vitally important.

2. There is no single moral theory or religious doctrine, which could offer a system of universally recognized values or anthropological ideas to address the rapidly increasing number of moral conflicts and difficulties.

3. Responsible decision-making on the verge of death requires transdisciplinary cooperation of medical doctors, biologists, philosophers, and other public experts on the one hand, and representatives of the public on the other.

4. The trend is that a public forum becomes an area of final decision-making. At the same time bioethics itself (through the feedback mechanisms) becomes a factor of public space formation.

Cloning, organ transplants, euthanasia, gene therapy, and eugenics - these and many other "incidents" (events) in the history of biomedical science of recent 
years due to their inherently paradoxical nature provoked and continue to provoke work of philosophers, physicians, biologists, lawyers, theologians and other experts, urging them to look for answers to the most pressing ethical and anthropological problems. These problems are the reason that pulls together efforts of experts and representatives of the public into a joint action and in this sense this is a foundation of their unity regardless of all the differences in their basic disciplinary positions.

Thereby grounded (and this means rational) decisions are made in an equivocal or bijudicious way (S.S. Neretina). Firstly, they are made in the context of the diversity of expert opinions (disciplinary justification in categories of the universal). Secondly, - in the context of a complex multi-level transdisciplinary dialogue as a general validity achieved by agreement. Thus, transdisciplinary communicative practices of bioethics at the borders with the life-world (in the border environment) form a new type of justification (rationality) of human actions in acute existential situations, which in the long run provokes exit into the borderlands.

For the bioethics casus the following statement of J. Habermas is quite truthful: "Ordinary life turns out to be the most promising medium capable to restore the lost unity of mind which earlier the expert cultures or yesterday's classical philosophy of mind claimed" [5].

Yet, restoring unity and consistency through communication practices of ordinary life, the scientific mind (both in the form of philosophy and the form of science) appears in the most serious crisis of the self-identity (self-identification). After all, it claimed to have a privileged access to the world in terms of truth (knowledge and power), exposing the prejudices of the ignorant representatives of the world in terms of opinions of the common people. And suddenly there is a situation in which achievement of integrity and justification, rationality of making a vitally important solution requires a kind of simplification.

The casus of "bioethics" is the source for setting basic philosophical problems - how can the paradoxical experience of transdisciplinarity exist? How can intelligent communication without generalization within a particular disciplinary perspective be possible? What are its a priori conditions? At the same time from the very beginning we already have the first of the conditions as an incident provoking thought, i.e. the case of "bioethics" itself. It is given here and now as a special kind of experience forcing philosophy to make a new step in rethinking of its grounds. This is a vital and practical condition for possibility of experience of the transdisciplinarity philosophy.

The philosophy of transdisciplinarity continues the tradition of philosophical knowledge to raise total theoretical and practical claims. Yet, by maintaining a thematic relation to the whole as its primary intention, it searches for the whole in counter streams, in the media of transdisciplinary communication on private and individual incidents of problem-oriented research tasks - casus. Interpreting a casus the philosophy of transdisciplinarity (following its generalizing intention) inherently comes beyond the limits of its singleness, suggesting some or other universal. The philosophical thinking can not happen without this component. However, on the other hand, every casus has an ability of generating not only one philosophical interpretation, but a whole range of possibilistic universal interpretations, each of which is special. Moreover, the base (unity) of this special general is just a single incident that constitutes their contextual definition here and now.

Therefore, the aim of our study is to clarify the conditions of the possibility of transdisciplinary experience, which appear to be paradoxical establishments, of the conditions for "a posteriori a priori" generating the philosophy of transdisciplinarity.

Given the limited volume of the article, let us consider the conditions of the possibility of transdisciplinary experience only in two aspects - from the point of view of the character of the existential mood and its most important theming.

\section{Transdisciplinarity: Unity by Mood.}

The experience of transdisciplinarity is immanent to the most radical understanding of the essence of philosophy. In this regard we shall recall the authoritative judgment of Merleau-Ponty that "It means also that philosophy itself must not take itself for granted, in so far as it may have managed to say something true; that it is an ever-renewed experiment in making its beginning; that it consists wholly in the description of this beginning, and finally, that radical reflection amounts to a consciousness of its own dependence on an unreflective life which is its 
initial situation, unchanging, given once and for all" [6]. The transcending move to the borders of the of the life-world is an extension to certain unreflective beginnings of philosophical (reflective) experience.

What kind of unreflective beginnings do define transdisciplinarity experience in the most proximate way? Here, of course, various options of comprehension are possible. Lets begin with a description of the specific existential mood, which paradoxically defines a fundamental unity - "unity by mood" (B.F. Porshnev, T. Shabutani). From our point of view, it is due to it that the divergent philosophical and disciplinary approaches to interpretation of reality, personal and craft preferences (forming the stereoscopy of the transdisciplinary research) can be retained in the conditional "frames" of a single research perspective. The unity of the mood creates an opportunity, a prerequisite for communication without a preliminary definition of its theoretical foundation.

The dynamics of human communities is set by the play of the dominant existential mood, defining a specific orientation for each culture between the poles of threat and salvation. The culture and science of the classical era are characterized by a linear disposition to fight the danger embodied in the external nature. At this salvation seems to be found in a rational scientifically based technical control over natural factors.

In modern culture the existential vector of the classical epoch remains, yet it is supplemented by an oppositely directed one. The threat of human existence is diagnosed not only in nature but also in the expansion of techniques and the dominance of objective scientific types of rationality. In this case, salvation seems to come by conservation or restoration of a person's natural environment. At the same time science paradoxically begins to play the role of a savior, and simultaneously, a role of an existential threat.

Thus, transdisciplinarity is based on a constant repetition in the game of hope and fear, their paradoxical convergence in a single human experience causing an existential aporia. Man hopes for a science-based technological solution of his own problems and is afraid of technology, in which he sees both a savior and the ultimate threat. The sustainable boundary for classical consciousness between "ours" and "theirs" is questionable. Life is grasped by the paradox of the existential mood into a specific integrity. "When we are thoroughly wrapped up in these moods - in which the world of meaning just "is" a certain way for us - we feel ourselves attuned to things in terms of their meaning-giving whole. Each mood has its own way of revealing the whole of things; and such revealing is not just any event but rather is the basic way in which human existence occurs" [7].

Of course, "the whole of things" is not a picture of the world and is not its certain reflecting idea as the object of experience. It is a primary, original puzzle ('enigma' according to V.S. Bibler) concealed in the subsurface of unreflective life of culture in its historically special materiality. This puzzle due to the highest existential significance captures a human being, and leads him to search for an answer, it leads to consciousness and puts each individual into the situation of a responsible act of choice of himself self-identification. As we show below, the requirement to identify themselves in terms of conducting a transdisciplinary experience, positions the cogitative in a multiple self-identity of conceptual characters (G. Deleuze).

And already at the level of existential mood a search vector has a different personality and temporal orientation. Depending on what meta-moment the ideal state (norm) is associated with, the whole diversity of possible reactions to a particular existential situation is divided into three conflicting groups. For conservatives the ideal state ("golden age") is localized in the meta-moment of the present-past. Therefore, their response to any threat (moral, political, or environmental) has the form of an antecedent restoration. For progressives the ideal state is localized in the meta-moment of the present-future. Their response to any challenge is a desire to create a new, rejecting both the imperfect and undeveloped ones - all that is brought into the experience from the past. Finally, for realists each situation is presented as a repeat of the previous one. In the structure of their responsible acting, the value of the tactics of restoration or innovation is situationally (pragmatically) determined.

Therefore, whatever real human problem becoming a "subject" of the transdisciplinary research we may encounter - in any case, the language environment of the cognitive-communication strategies will be structured by conflicting positions, which are based on the structure of the temporal value preferences. For example, every time a problem of trans- 
disciplinary risk assessment arises, or that of a threat or the degree of usefulness of a technological innovation, the expert community and the audience are immediately divided into three above described conflicting groups who are unable to reach an agreement at the level of knowledge which is always loaded with personal preferences. They are united by a common basic mood, which, through the use of written and unwritten rules of "language games", provides resolution of the conflict and achievement, of though not understanding (consensus), then at least an agreement (compromise) on matters which touch a chord of each communication participant. The Participant of communication, "stung to the quick" becomes personally responsible for the meaning that he cannot shift on the mediation of any anonymous, collective and general instances. Assistance in mutual understanding arises through recognition of the right of everyone (openness to another) for understanding (creation) of newly preset meanings.

The above-described paradox of the existential mood, structured by the play of temporal and personal preferences, is the first one we found in the course of discussing the conditions of the transdisciplinary experience, directly woven into the dynamics of unreflective life. Provoking and setting up thinking on a particular "wave", it creates some limiting conditions for it, and predisposes to the revival of the already established themes of philosophical and scientific research and to initiation of new ones.

\section{The Theme of Transdisciplinarity}

Let us note that the word "theme" was expressed not coincidentally. In our understanding of the knowledge genesis dynamics in the sphere of the life-world we rely on fundamental ideas presented by J. Holton in his book "Thematic Origins of Science Thought". For us Holton's approach is important because he is searching for the origins of science in the place where transdisciplinary experience is set - in the structures of the life-world. It is no coincidence he works not only with scientific and philosophical texts, but also with diaries, letters, interviews, laboratory journals and general educational programs. Holton notes that the thematic structure of scientific activity can be considered to be largely independent of the empirical and analytical content of research. It manifests itself in the process of studying the choices that are in principle open to a scientist [8]. Holton's idea of theming is on the one hand labile enough to hold the internal complexity of scientific experience, its forming nature, and, on the other hand, to express some repetitions (non-conceptually represented universality) in the development of both scientific and philosophical thought.

The paradoxical play of the modern type existential mood imposes repetition of a whole series of traditional themes (which we understand as paradoxes) on sciense and philosophy: of power and vulnerability of the human mind, freedom and determinism, part and whole, reductionism and holism, preformationism and epigenesis, creationism and gradualism, individual and social, natural and artificial, etc. These themes (paradoxes) are proliferating ties of multiplying bioethical conflict plots. In the everstretching network of the paradoxes we select three nodes which are most significant for understanding the philosophy of transdisciplinarity: the paradoxical relation of unity and multiplicity, philosophy and sophistry, and the transposition of philosophy.

\subsection{Unity and Multiplicity}

Metaphysical foundation of technological exploration of the world has been a setting for theoretical grasp of some pre-existing in God, nature, reason or transcendental conditions of scientific experience of the unity. Multiplicity was perceived as a threat. Awareness of the loss of unity was a cause making, according to Husserl's expression, the philosopher think. "Fragmentation of modern philosophy, and its fruitless efforts make us think. Since the middle of the last century, the decline of Western philosophy, if we consider it from the point of view of scientific unity, compared with previous times is undeniable. In setting of a goal, problems and methods this unity is lost" [9]. The modern "thought-provoking" attitude is more paradoxical. It maintains continuity with classical rationalism - philosophy and science can not search for those or other common grounds. Yet, today, in a certain sense, the danger is recognized in the very desire of the 'only' unity, of the only ground. Now the search is carried out to find grounds to justify the "fragmentation" itself, to justify the objectivity of pluralism (according to E.A. Sidorenko) [10] and multiple nature of the mind. We are going to cite as examples the concept of culture as a dialogue of cultures by M.M. Bakhtin, the logic of dialogue logic by V.S. Bibler and transcendental empiricism of J. Deleuze. The dialogism (no matter 
how it is understood) becomes additional (compared to monologism of the classical rationalism) prospect of relations not only to another (reason, understanding, etc.), but also to the other in the form of nature. It is especially well worked out in the theory of selforganization (synergetics). Scientific knowledge is transformed into an experimental dialogue with nature. The "vision of nature is undergoing a radical change in the direction of multiplicity, temporality and complexity" [11].

Ontological foundation of scientific and philosophical approaches, trying to realize the multiplicity of possible unities is a paradoxical idea of "deterministic chaos", shifting the focus from the question of existence to the question of development as the element that generates possible ontological and logical options of order (of the universal). Yet, this shift does not mean "removal" of the question of existence. Two types of questioning are in a tight contact of additional search strategies "of the law in establishing process and the game of necessity" [12]. We deliberately emphasized the importance of situations of aporia and paradox in the casus of "bioethics" that are variants of discursive deterministic chaos.

Heraklitus' "polemos" is reigning in the polyphony of becoming and arguing with each other scientific and philosophical perspectives [13]. Such a "polemical" interaction of diverse forces, tied in bioethics into a joint action, may have an unlimited number of variations - from ideological quarrels to synergy motivated by the achievement of mutually beneficial consensus. However, both in this and that case, the "polemicists" feel the need in each other in order to become themselves. In the fight they are 'communicated' to each other, they are together in it.

However, if neither in God nor in mind or in nature we assume "the eternal law" or the principle of unity which is universal for all, here is the the question what can one hope for when facing acute existential problems? How can communication come without generalization? How is it possible to think not only the unity of the manifold (the dialectics is quite good at that), but also the variety of possible unities? The interest of the "bioethics" casus lies in a helpful hint - a spontaneously found vital and practical solution. In response to the difficult life paradoxes arising from the development of biomedical technologies in the 60 s we began to form ethics committees that by the beginning of this century have become an institutionalized form of bioethics presence in the structure of the modern type of science. The answer is formed in the context of the joint communicative transdisciplinary effort (dispute or discussion). At the same time, the doctor does not cease to be a doctor and the philosopher does not cease to be a philosopher.

Their expert positions (definitions in the categories of the universal) arise in response to existential aporia, breaking naive general validity of ordinary notions about life, death, and human being. They are urgently needed for a reasonable answer to the problems identified, yet they are insufficient. They are made sufficient by a joint transdisciplinary effort to achieve through the procedure of public discussion of a generally valid agreement concerning the assessment of unfolding events. The general validity reached by agreement (as if it was universality), for example, in defining the "brain death", on the one hand gives legitimacy to certain biomedical practices (in our example - to those in transplantation), and on the other it provides congruence of confronting disciplinary perspectives in the form of a kind of a social contract.

However, no matter how useful the concept of the social contract is, it does not remove responsibility from philosophy for the very philosophical understanding of its participation in the transdisciplinary bioethical communications. We believe that an important step in this kind of thinking is the idea of "unpretentiousness philosophy" belonging to J. Habermas which (and this is essential) is formulated by him in the context of discussion of liberal eugenics projects [14]. What is the meaning of the unpretentiousness of the philosophy of transdisciplinarity? In this case the philosophical search for a universal foundation correlates with communication strategies of detecting general validity in the variety of disciplinary unities. Thus, the setting for universality, matching with the achieved general validity, forms a universe of transdisciplinary discourses.

According to Habermas, the naive identification of own private prospects of discourse with a certain self-evident position of the universal proved its irrelevance in the modern philosophy. The assumption of a universal, one for all existing perspective of truth or idea of the good life, which has recently inspired the philosophical community concerned about loss of "unity", is not just put in question. It is itself, as such, perceived as a threat of an unacceptable interference into the right of every person "to develop ethical 
self-understanding in order that, in accordance with their own abilities and good intentions to implement in reality a personal concept of "the good life" [15].

Yet, here is a question - is unpretentiousness of mind a manifestation of its impotence? What the philosopher can hope for, unpretentiously proposing judgments, in particular, about the ethical acceptability or otherwise, for example, of liberal eugenics? What can the humanity hope for in the face of existential threats? In modern democratic secular society references to God are relevant only within the community of coreligionists. In this situation, Habermas offers his variant of "Other" "weakened by proceduralism" as a language or communicative practice. According to Habermas, not only a correct moral judgment, defining the relationship between the subjects, but also the correct ethical self-understanding cannot be obtained by revelation, or "given" in any other way. It can only be won by joint efforts" [16] (our italics - L.K.). From this perspective, only the joint communicative effort may give a reasonably well-founded answer to the question about the moral acceptability of the ideology of liberal eugenics, as well as any other issue in transdisciplinary situations. Language as "self-explanatory of human nature" (Marx), presented in the communicative community is a foundation of our hope in the face of an avalanche of multiplying existential threats.

By challenging the presuppositions of another, permanent process of nomination, criticism and rejection of failed judgment and selection of successful suppositions concerning the possibility to be oneself in the face of each other, the participants of communication are moving towards understanding of the common good, the basis of which is the fact of the agreement reached. Yet, the idea of the common good is unusual here, it represents common understanding of how people with different views of fundamental life values can live together. I.e. it is the principle of retention of difference and preservation of polemos as a ground. It is no coincidence that in fact the principles and rules of bioethics are not common "solutions" of problems, but the rules of competition of different value orientations in the space of the public dialogue.

It is natural that the guarantor of the reached "universally valid by agreement" is not some universal logic, but determination of communication participants to comply with each other's obligations. The joint effort of moving to the transposition with another in response to his counter-desire to be implemented together strengthens the position of philosophizing in transdisciplinary researches and gives the most common answer to the Kantian question - What can I hope for? The hope is for that more which is being revealed in a communication community bound in the face of most acute existential problems via the common mood. It is this kind of transdisciplinary communicative community that modern bioethics represents as an idea.

Only in the context of the joint communicative effort the possibility of co-presence is retained in the experience of variety of disciplinary believed unities. What is the relationship between them? We are going to use the discussion of the second theming to clarify this issue.

\subsection{Philosophy or Sophistry?}

The subject of transdisciplinarity can be viewed as a recurrance of the conflict between philosophy and sophistry. And this is such a repetition that creates resources for its new interpretation. As N.S. Avtonomova eloquently writes: "Once in Greece, during the times of the Second sophistry, the philosophy won over rhetoric, the proof - over belief, the objective thought - over achievement of some external goal. In the present situation the rhetoric in the world culture took revenge on philosophy, subordinating its objective aspirations to functional justification. And now, perhaps, it would make sense to return rhetoric to the service of philosophy" [17]. We agree with the relevance of the theme thus posed, yet we consider it to be counterproductive to use the language of victories and defeats. The return of sophistry and its rehabilitation is not a rejection of its "thingness" and "objectivity", yet a desire to find the means to comprehend their forming (disappearing and appearing) character. Testing of "objectivity" and "thingness" projects is held at a public forum of all interested participants, which at the same time becomes a platform for practicing methods and abilities to form their own opinions. This is not a result of lack of respect for truth but rather a discovery of its "human-like" character[18]. The truth reveals its "human-likeliness", as it has been mentioned above, in crisis situations, during failure of established norms, unwritten rules when something alien puts its presence through resistance. "Available means of communication" and rhetorics reasoning, evidence and demonstration of probabil- 
ity and other techniques are used with the aim to generate by means of language and extra-linguistic means certain emotions and feelings that can in turn lead to new directed formation or modification of the original perception stereotypes and behavior. [19].

The desire of the mind to stand on the God's point of view stands behind the objectivism. B. Russell in order to express this tradition of philosophy writes: "The free intellect will see as God might see, without a here and now, without hopes and fears, without the trammels of customary beliefs and traditional prejudices, calmly, dispassionately, in the sole and exclusive desire of knowledge - knowledge as impersonal, as purely contemplative, as it is possible for man to attain" [20]. Yet, it is precisely the fact that these points of view can be infinite. Philosophy is a complicating variety of philosophies, each of which offers its own unique project of the world as a whole. Therefore, there is a special need in a human and his private perspective (here and now), the introduction of which is necessary for understanding of the unity of the diversity through keeping of the diversity of virtually existing unities in the experience.

There are powerful resources in culture to keep human and divine, human-like and objective, philosophical and sophistical distinctly and inseparably. It is sufficient to refer to Peter Abelard's conceptualism in the interpretation of S.S. Neretina, from which we borrow (although in a redefined form form ) the ideas of equivocation (bi-meaningfulness) and concept [21]. With regard to the concept we also take into account the approach proposed by Gilles Deleuze and Pierre-Felix Guattari [22].

The idea of equivocation or bi-meaningfulness in our interpretation suggests an immanent twostroke thought process. It implies that the active role is played not only by reflection determining the specifics of theoretical thought process, but also the intellectual procedure which we would call a "transflection". In our opinion, the transflection is a specific method of justifying the "unpretentiousness of philosophy", which differs from the classical method of philosophical reflection by taking into account the nonlinearity of communication events. The concepts of "non-classical", "synergistic" or "specific" reflection [23] are very close to our ideas.

Metaphysics of the traditionally understood reflection involves a turn, reflection from the object and return of a "ray of light" of the natural mind. Reflection holds that in the subject what (reflection might be such a subject itself) is implicit before the act of its display. The self-identity is the main characteristic both of the being and of the reflexive technique subject aimed at understanding of the preexisting impersonal divine or transcendental true foundation of thinking. The identity of the reflective experience is provided by the idea of pointness of the "cogito" itself and the transparency of the medium (language), in which the cognitive activity is carried out. The transflection implies conversion of a uniform field of reflection, replacing of "I"-spotting or the "subject" of transcendental philosophy with the concept of a sophisticated selfness, implying a multiplicity and immanent presence of non-reflexive, anonymous, incapable of rationalist reduction body experience. In the transflection horizon the experience densifies due to the complexity of the synergistic relationship of the participating agents (cognizing subjects, language, mood, cognitive tools, experience and environment, etc.)

The sense of a classical reflection is a recognition of the identity in oneself (self-identity) and in the other. Therefore, it is inherently retrospective. The transreflection is set by amazement and is focused not on learning, but on "the fundamental meeting" (G.Deleuze) with otherness in itself and the other. In this sense it is prospective and is revealed to the unknown risky future [24]. Otherness is rhythmically structured by the dominant existential mood. It keeps the plan of integrity as a fundamental mystery (problem), whose solution is the aim of transdisciplinary communicative activities of scientists and philosophers.

If philosophical or other disciplinary points of view are self-identical, and like "mental atoms" are reflexively self-absorbed, they do not need any kind of dialogue and, in fact, are not capable of it. They do not need it since they are seeking only the identity in themselves and identity to themselves. Since they are self-sufficient. A different view or a different perspective is just an annoying otherness, which shall always be possible to "remove" after considering it as a particular case, an abstract moment, stage of development, or simply meaningless deviation (error) of the self-identity of the appropriate and true. They are not capable of that since they deprive themselves of a meeting point with another by not recognizing and pushing the otherness out of themselves.

The communication community is based on the mutual need of others in "others" for self - 
implementation. This is its grounds. The transflection as a justifying procedure, is designed to keep a zone of openness to each other and need in each other (tolerance towards oneself and others), to protect against reflexive "withdrawals". Reflection and transflection do not reverse each other. They are in contact, defining (setting limits) and redefining the Kantian question "What can I know?".

The fact is that, firstly, in a situation of a real transdisciplinary dialogue the ' $\mathrm{I}$ ' itself opens a space of possibility to become another - becoming the multiplicity of identities, each of which implies its own form of justified knowledge, which is carried out in the opposition of universal and generally valid. Secondly, my "I can know" includes the result, which can be obtained and specifically justified only in the communicative "together" effort. Of course, I can successfully express an opinion which then will be taken as a universally valid by agreement. Yet, I can not claim to its sufficient justification to be accepted by others from inside the prospects of my specific general (my personal and disciplinary understanding).

Therefore, it is important in the word can to keep not only the cognitive plan, but also a communicative one - I can know what I can tell the other (assuming intersubjective universality or general validity), as well as something more - something that can occur, and it is in that area, where intersubjectivity comes into question. We are going to look at this aspect later when we turn to the issue of transdisciplinary translation.

Next (and this results from the previous one), the "I can know" includes a condition of communicative competence (K.-O. Apel). It marks the feature of such knowledge which is possible to use as an argument in a dialogue with others as opposed to the knowledge, which I just know, but I can not use. It is especially important for bioethics. Theoretically people, such as patients, can know about their rights, yet they do not have the knowledge-skill to implement these rights in real social interactions.

If the expressive tool of reflection is a notion, then the transflection as a method of the unpretentiousness philosophy works with concepts. They are forms of a thought operating in the mode of direct dialogic communication of a speaker and listener, a writer and a reader. This is particularly evidenced by the Latin etymology of the word "concept", which is derived from the prefix "con" (to act jointly, to in- teract, be compatible) and the root "cept" (take, accept, get).

From our perspective, the existential energy of the aporia of life incidents (casus) and the paradoxical experience of their comprehension is concentrated in a variety of paradoxical problem nodes - concepts as germs of thought ("dispute" - V.S. Bibler). For example, the development of heart transplantation techniques identified the concepts of 'life' and 'death' as being such a problematic node (the subject of the transdisciplinary dispute). The meaning of the paradoxical situations that arise in connection with the progress of new reproductive technologies (abortion, in vitro fertilization and embryo transfer, cloning) is concentrated in a specific bioethical concept of "human" (T. Sidorova). The paradoxes of the new models of relationship between doctors and patients are embodied in the "personality" concept. The concept links the spheres of life and thought in a speech, pointing to a possibilistic (V.S. Bibler) nature of their correlation, but not leading this possibility to complete actual "intake of the idea of being, or the thought being" leaves as a significant the uncertainty, fundamental mystery (paradoxicality), which actually forces one to think. It is rhythmically structured by the play of the dominant existential mood.

The concepts common to the whole field of transdisciplinarity provoke diversity of scientific research areas which are aimed at finding philosophically, theologically and disciplinarily justified solutions having the form of conceptual seizure. However, the paradoxical complexity of existential problems is that (as it has been already mentioned) none of the disciplinary reasons even if it is necessary can claim to sufficiency. Both in the question of the beginning of human life, and in the question of the final moments of human existence, and in other less acute existential situations the polemos is reigning, shrinking the diversity of minds (scientific, philosophical, religious), truths and ideas of the good, understandings of the truth of human existence into the aporia of a single space of the dispute. The concepts, being extended by paradoxes of conceptual seizure, generate a paradoxal momentum for finding the roots and validity in the field of transdisciplinary communications of the life-world.

Thanks to the transflection retention (seizure) of "more" as a fundamental enigmacy (unreflexive), the concept, as a form of dialogical speech, preserves an open space for another as a fundamentally different. 
In it, as in an "embryo" of the thought, "the makings" are always presented, embodied in the speech of at least two participants of the dialogue, their original argument - polemos.

In contrast with the definiteness of the notion, the concept (due to its paradoxical nature) is initially underspecified. For classical thinking uncertainty of cognition and mutual understanding had 'subjective' character of the intelligence insufficiency. In modern science and philosophy it becomes "objective", pointing to formation as to an intrinsic property of the reality itself. The concept is "living" in the between-speech of those holding a conversation, inseparably and distinctly reproducing in itself subjective and objective aspects of the interlocutors speeches, as well as reproducing the more retained by the transflexion. For this reason it is acting as an indispensable "intermediary" of the dialogic communication or "communicating without generalization" of the transdisciplinary communicative translation experience, localized in the border zone between the language of everyday life (the word) and disciplinary discourses (the notion).

Here we are approaching the next important distinction between the notion and the concept. The logically related scientific theory (or theoretical model) is an expanded form of the notion. Intradisciplinary, binding the paradoxicality of the notioncatching (possibility of alternative theories), the concept is unrolling into the conception [25]. Within philosophy (its special areas such as ethics or anthropology), theology, biology, medicine, psychology, and other disciplines, the conceptions of person, personality, death, life, etc. are formed driven by the energy of concepts.

Concepts take the form of conceptual narrations in the transition to the transdisciplinary communications field. Unlike conventional narrations structuring relationships in the life-world, the ties of the conceptual narrations and their vicissitudes structures include the above marked existential aporias, paradoxical semantic clots of which are precisely the concepts [26].

In the transdisciplinary communicative practices the speech of an expert represents a betweenspeech of at least two speeches - the first one is a disciplinary-oriented logical statement of objective truth, the other one is focused on the rhetorical (through the narrative presentation of the situation) conviction of another. At the same time, if disci- plinary discourses are self-closed, in narrations their unlocking occurs towards each other. P. Ricoeur, discussing the problems of the dialogue of Sciences and Humanities concerning understanding of the nature of human action, indicates that the narration is a natural "high-level meeting place" for dialogue (dispute) of the diverse options of the moral and theoretical reason [27]. This is achieved by a possibility of translation of the disciplinary knowledge into the language of narrations that simulate possible projects of human existence in the structures of the life-world in the form of results of research or their moral evaluation.

The transdisciplinary communication being a mediated translation of disciplinary knowledge into the language of narrations, models specific forms of common life activities of individuals trying to resolve existential paradoxes packed in the concepts. For example, a scientist (biologist), who invented a new technology, shall (in order to get the message meaning of his discovery across non-specialists) translate their results into the language of the life-world narrations. Thus, he seems to be forced to expand the scope of an experimental dialogue with nature, moving the dialogue itself into the experiment to harmonize his positions with the moral positions of other subjects [28]. Simplifying, we can say that he needs to present his discovery through the narrationexpressed versions of new prospects for solving specific human problems: treating diseases, making life easier, improving quality of environment, etc. Exactly in the narration-structured environment of the life-world, the existential aspirations of scientists and their assumptions about the meaning of good come into conflict with the completely different aspirations and assumptions of other participants in social interaction. Vital-practical tragic aporia arise (as noted above) and are condensing in the concepts.

It is these primary narrative representations (nodes and plot strings of which the concepts are) which philosophers, lawyers or psychologists start to work with. Based on the narration as on the original empiricism, they (each in their own way) conduct professional research and, thus, translate them into specific languages of specific disciplinary areas. As a result of these studies they may come up with their own interpretation of the meaning and moral value of the scientists discovery. However, the clarity of judgment of a philosopher, psychologist or any other expert to others (non-experts) again can only be 
achieved as a result of the reverse translation of the results of philosophical, legal or psychological analysis into the language of narrations of the life-world. The meanings and evaluations identified by them shall be retold as open or closed versions of life stories which are possible as a result of implementation or non-implementation of biomedical technologies (for, example, permission or prohibition of human cloning).

In this sense conceptual narrations, representing the life-world structures, are transdisciplinary communication mediums. Concepts are the sources of meanings generated as a result of direct and inverse translations. Transflection keeps nonlinearity of the dialogue in a variety of concepts, highlighting contingent islands of stability (validity by arrangement) in the formation and exchange of meanings and maintaining a productive zone of mutual untranslatability. At the same time the mutual untranslatability of languages used be transdisciplinary communication partners (unsolvability of fundamental paradoxes) is valuable as a sense-generating zone. As Y.M. Lotman emphasizes: "Value of a dialogue turns to be connected not with that intersecting part (the intersections of the speaker's and listener's language space - L.K.), but with the information transfer between not intersecting parts. It places us face to face with an insoluble contradiction: we are interested in communication precisely in the circumstances which make communication more difficult or even impossible. Moreover, the more difficult and inadequate translation of one of the non-crossing parts of the semantic space into the language of another is, the more valuable becomes the fact of this paradoxical communication in information and social terms. One can say that the translation of what is not translatable is a carrier of information of great value" [29]. The act of thinking which is carried out during this kind of translation is an option of the transflection discussed above.

In the above analyzed interamnian of transdisciplinary communications voices of a philosopher (in its classical sense) and a sophist are only situationally distinct self-identities of inner and outer speech of a real philosophising individual, whose specific position (trans-position) we are going to consider now.

\subsection{Transposition of Philosophy}

Let us distinguish three possible thematic positions of philosophy in relation to the experience of transdisciplinarity, taking into account the way they unfold in the casus of "bioethics". These positions determine the 'place' of a thinking person and his self-identity which, following Gilles Deleuze and F. Guattari, we are going to call a conceptual character. First, we note the position of a detached Observer, which is historically assigned to the modern European philosophy. Philosophy is thinking about the transdisciplinary as an object existing in the context of a new type of science. This form of a reflexively established self-identity of a thinking person is characterized by paradoxical positioning - to be outside the world (this allows to understand it as a whole) and in contact with it, on its border. When, for example, Descartes, methodically questions everything, and escapes from everything, his only task is to find the absolute foundation of meaningfulness of all this everything. His individual effort of a single human being opens up a universal associated with a divine point of view.

The feature of the theming is, in this case, that the human effort is being eliminated from the result - an integral vision of the world. It does not have an ontological status and refers to the empirical visibility. In this respect, thinking about the transdisciplinary does not change anything in the subject of the thought. Any reasoning about genes, clones, organs, moral principles or rules naturally reproduces this transposition of a self-identity of a philosopher or a scientist in a situation of transdisciplinary. There is a notion about the uniqueness of the universal (the truth) in its basis, claiming both for the integrity and the universality. This is a basic and reflexively justified position of the disciplinary knowledge, from which the expert idea is put forward by concepts into the situation of the transdisciplinary dialogue and to which they keep coming back for the purpose of conceptual seizure of the unfolding events.

The second form of the transposition of philosophy is congruent to the position of the knowing mind in the non-classical science (V.S. Stepin), for which the effort of the learning individual, objectified in the language and instrument, becomes observable itself. The objectivity of science gains features of the human presence and the subject of its research acquires people-dimensionality [30]. We mark this position 
as a position of the Participant. The philosopher is not only thinking about bioethics, yet he becomes himself an active participant of the transdisciplinary communications. His thought, his effort as of a real individual, is an event changing the condition of the object of his thought.

In the transdisciplinary experience the objectivity of disciplinary areas is marked at the time of formation, experiencing a reincarnation of its own beginning, and therefore it appears as unstable (appearing and disappearing) [31, 32]. Correlatively the self-identity of the Participant is also unstable and is formed along with the objectivity. But precisely in this unsteady transient transdisciplinary state the scientific disciplines become open to a meeting with other forms of disciplinary scientific knowledge, religious experience, and 'applied knowledge' (M. Heidegger).

If we use the scheme of a subject-object relation, in this case the classical form (first form of the philosophy transposition) is radically complicated by the variety of ways of interaction paradoxically presented in it. Universal definitions of disciplinary knowledge can no longer claim to integrity and universality of understanding of the happening. To achieve it, the diversity of the universal is extended by "as if the universal" - the generally valid, achieved as a result of cognitive and communicative practices of transdisciplinarity.

Transflective retention in concepts and conceptual narrations of a large enigmatic transdisciplinary experience is turning the border between the learned and not learned, between what can and what cannot in principle be scientifically known, into a communication channel with other forms of the mind (for instance, religious) and other forms of spiritual experience.

Retention of dual understanding of this transposition is a paradoxical event. The Participant of transdisciplinary communications regulary becomes an Author producing in the word and in the deed results of his observations, or a Hero of his own judgments (narrations) about transdisciplinarity as a possible object of a thought. He is both the one responsible for his choice, claiming to the universal, and the one who is already tragically inscribed into a specific situation, defined by generally valid values and personal preferences. He is inside and outside, he is free and to the same extent determined and defined in his decision by something external or some mysterious inner freedom. At the same time the Participant for himself and for another plays a paradoxical role of complementarity characters of conceptual narratives - of an Expert and an Outsider.

It is in this variety of paradoxically presented ways of interaction analyzed in this transposition, where each participant, leaving the scope of his private position (including the disciplinary one) in the transdisciplinary experience is a potential philosopher. Interpretation of these circumstances, in fact, refers to the third transposition. Yet, still it is naive. Human (universally valid) and divine (universal) enter into a complicated game to comprehension in the third position. A disciplinary philosopher, after going through the transdisciplinarity practice in the "bioethics" casus, enters the third transposition.

The third transposition of philosophy, which we denote with the word Witness, as it seems to us, is an embodiment of the philosophy of transdisciplinarity phenomenon as such. Keeping connection with a vital and practical casus, advancing into the transdisciplinary experience under the imperative pressure of concepts, turning the answer in the conceptual universality of the Observer and contextual validity of the Participant, the Witness constitutes himself as the one who keeps the distinction (polemos) of the two above mentioned conceptual characters and provides the experience of their bound execution. He keeps the original paradoxical feature (deterministic chaos) of the transdisciplinary experience, which, as causa sue ensures its constant repetition in multiple existential situations generated by biotechnological progress.

Each of the trans-positions is characterized by its own "voice" or, to be more precise, by its own "speech". Speech of the Observer strives to turn into a logically connected reasoning, expressing some true state of affairs. The truth is the alleged basis of this position. In terms of expression the Observer becomes an other conceptual character - Subject. The speech of the Participant, without abandoning the intention for the truth, brings into the situation an element of relativity, dependence on a private (individual) decision of the observer, which itself is not justified and quite accidental. Such conceptual characters as Author, Hero, Reader, Expert, and Layman constantly appear and disappear in this equivocal speech. The Witness's speech, keeping the truth attitude as a basis, and taking into account 
the relativity and multiplicity of truths, introduces its own act of witness (attestation according to Paul Ricoeur) as a justifying one through personal identification in a responsible act. The Universum of the Witness's judgments is unrolling in a paradox of two simultaneously present limiting assumptions of "universal" and "generally valid". In a very strict sense, the Witness is a one who as a unique human individual, evidences the reliability of the "divine" and general validity of the universal. And the strength of this evidence depends not only on the truth open to it, but also on Witness's luck to get two gifts of real existence - attention and recognition of it by others. [33]. These others - there is a communicative community, which in respect of evidence plays the role of the Judge, whose decisions are taken in a joint communicative effort. This is the meaning of the transposition of the unpretentiousness philosophy in our understanding. Naturally, a product of a special kind should be an embodiment of this experience of philosophizing, which we call the open one[34]. To be open in the sense of the inherent incompleteness, addressing the search for self-justification, to the really other, as to the other Witness, and Judge.

By playing the Witnesss role, the philosopher is trying to track events of emergence and interaction of two above mentioned positions and of himself in this interaction. Significantly, the transposition of the Witness is pinpointed just before, in the border situation of the act of a responsible choice, and is not just a choice of a particular action (that's his business as a Participant), but also the choice of the "self" as responsibly (in reply to the question raised by an existential situation) acting in a given place and time. The transposition of the Witness inherently contains the ethical dimension of the ambiguity of the choice. What answer may be given to the Kant's question "what should I do?" in such a situation? What kind of responsibility is meant? Obviously, in paraphrasing Deleuze phrase, we can answer that in order not to be responsible for the victim, it is necessary to simultaneously hold the responsibility towards them.

Let us make some conclusions by summing up our arguments. Firstly, in contrast to the classical science, which is ideally a closed system, the transdisciplinary experience is a new form of production and generation of knowledge as an inherently open system. Traditional forms of disciplinary scientific knowledge are generated in this experiment along with a wide range of common, religious and other forms of knowledge. In addition, all these forms are associated in the framework of the universal knowledge achieved by a joint effort, associating and keeping more, the variety of universal definitions and the generally valid by agreement. Secondly, the conditions of possible transdisciplinarity experience are: casuses of life-practical situations, paradoxical play of the existential mood, a wide range of thematic paradoxes, network of concepts and suspension of conceptual narrations, as well as three major transpositions of philosophizing, which the network nodes (conceptual characters) of the philosopher self-identity are arranged around.

Due to the border nature of the transdisciplinary situation these conditions both precede an experience and are newly redefined in it, and become different (being generated in a certain sense). From our point of view the conditions of the possibility of transdisciplinarity experience (in its philosophical and scientific aspects) considered in such a way, appear in the form of a network of paradoxes. It operates according to the causa sue principle, constantly renewing (provoking) cognitive and communicative practices of the transdisciplinarity (the "production" of knowledge).

The philosophy of transdisciplinarity, slightly adjusting Nancy's statement, when still thinking about questioning, continues to think "about the answer: though not about the response-decision or the response-verdict, but about the co-communication. In co-communication which is our co-responsibility, we do not need someone who impedes the communication, but on the contrary, who establishes it and gives a new impetus" [35].

In the situation where humanity is once again losing its unity, internal stability, and finds itself in a threatening and fascinating abyss of chaos and where a wave of new barbarism is scouring its cultural base, the transdisciplinarity experience, and this is what we tried to prove, sheds the light on the positive meaning of the current existential crisis situation, in which culture refers to its own flesh and the matter of re-creation [36] .

Funding: This research received no external funding.

Conflicts of Interest: The author declare no conflict of interest. 


\section{References}

[1] Kiyashchenko, L. P., Tishchenko P. D. (2004). Experience of limit - strategy "resolution" of the paradox in cognition // Synergetic paradigm. Cognitivecommunicative strategies of modern scientific knowledge. M., 104 p.

[2] Actually, the Bible is a collection of 'casus' of the divine revelation in actions of the prophets, Christ, and the Apostles.

[3] Shemanov A.Yu. (2011). Problem of foundations of bioethical discussions and uncertainty of sledidentification of modern man. In: In space of biologos. SPb., P.101

[4] Akhutin A.V. (2005). Invention of consciousness (Antique tragedy and philosophy) In: Turning times. M.,. P. 162, 164 (In Russian).

[5] Habermas J. (1995). "Philosophy as Stand-In and Interpreter" in Moral Consciousness and Communicative Action. Translation by Ch. Lenhardt and Ch. Weber Nicholsen. MIT Press, Cambridge, Massachusetts. P. 29

[6] Merleau-Ponty, M. (1999). Phenomenology of Perception. SPb. PAGE 13

[7] Heidegger M. (1993) What is metaphysics? // Being and time. Articles and speeches. M. P.20

[8] Holton J. (1981). Thematic Origins of Scientific. . Page 8.

[9] "Fragmentation of modern philosophy, and its fruitless efforts make us think. Since the middle of the last century, the decline of Western philosophy, if we consider it from the point of view of scientific unity, compared with previous times is undeniable. In setting of a goal, problems and methods this unity is lost" E. Husserl (1998)Cartesian Meditations. Translated by D.V. Sklyadnev. Saint-Petersburg, P. 54

[10] Sidorenko E. A. (2002). Logic. Paradoxes. Possible worlds. (Reflections on the thinking of nine essays.) M. P.96-153.

[11] Prigogine I. Stengers I. (1986). Order out of chaos: Man's new dialogue with nature: Translated from English/General editing by V. I. Arshinova Y. L. Klimontovich and Y. B. Sachkova. M., P 34.

[12] Deleuze G. (2003). Nietzsche and philosophy.Translated by O. Khoma M. P.85

[13] According to Heraclitus - "We must know that war is common [all being as a community, where everything is made known to everyone and wherein all and everyone are in together] to all and strife is justice, and that all things come into being through strife [everything is covered, seized by strife] necessarily." (Quoted from: A. Akhutin (1997) "The lawsuit about the Genesis" . P.7). These "strifes" of Heraclitus (as the "contractions" of a woman) are a form of the primordial origination of the world.

[14] Habermas J. (2002). The future of the human nature. On the way to liberal eugenics? M.

[15] Ib. P. 3.

[16] Ib. P. 8.

[17] Avtonomova N.S. (1999). Notes about philosophical language: traditions, problems, perspectives. In: Problems of philosophy. No. 11. P. 28.

[18] See: Vasilieva T.V. (1995). Eternal truth of Protagor. In: Ache. N 4., P. 206.

[19] The thought and the art of argumentation. M., 2003.

[20] Rorty R. (2004). Universalist Grandeur, Romantic Profundity, Humanist Finitude. M. P. 9.

[21] Neretina S.S. (1999). Middle-aged thought as strategema of contemporary thinking. In: Problems of philosophy, N 11. P. 122150.

[22] Deleuze J. , Guattari F. (1998). What is philosophy? M., SPb. P. 23-47.

[23] Avtonomova N.S. Reflexion in science and philosophy. In: Problems of reflexion in scientific cognition. Kuibyshev. 1983. PAGE 23.

[24] In the reflection-based goal-setting a goal - since it is set at a specific moment - becomes a moment of the past in the next one. Therefore, the action in the horizon of the goal set is not an advance in the future, and return to the sphere of the the former, movement forward with the head turned back.

[25] Neretina S.S., Ogurtsov A.P. (2001). Concept. In: New philosophical encyclopedia. V. II. M.,. P. 306.

[26] The concrete examples of conceptual narrations can be found in the book by Tishchenko P. D. (2001). Bio-power in the era of biotechnology. M.

[27] Ricoeur P. (1992). Oneself as Another. Univ. of Chicago Press,. P. 113-115.

[28] For more details refer to Kiyashchenko L.P., Tishchenko P.D. (2004). Philosophy of transdisciplinarity as experience of practical philosophy. In: Practical philosophy (Kiev), , No. 2-3.

[29] Each expert in relation to an expert from other scientific disciplines plays a role of a layman. 
[30] Lotman Yu. (2004). M. Culture and explosion. In: Lotman Yu. M. Semiosphere. SPb., P. 16.

[31] See. The philosophy of science. Issue 8. Synergetics of objects proportional to the person. M., 2002.

[32] Kiyashchenko L.P. (2000). In quest of vanishing objectivity/ (Notes related to synergetics of language). M.,

[33] Kiyashchenko L.P., Tishchenko P.D. (2009). Ellipsis of situation between speeches: experience of bioconcepto-graphy. In: Languages of cultures: imageconcept-image, P. 129-155.

[34] We use hypothesis of U.Eco about presence of a stable model of opera aperta (open creation). He was based on the fact that the system of relations at different levels (semantic, syntactic, physical, emotive; level of themes and level of an ideological content, level of structural relationship and a structured answer given by a receiver, etc.) has a similar structure of creation writing - use. See: U. Eco. (2004). Open creation: form and uncertainty in modern poetry. SPb. P. 13.

[35] Nancy J.-L. (1998). Responsible for the existence. In: Intensionality and textuality. Philsophical thought of France. XX century. Tomsk. P. 316.

[36] Batkin L.M. (2001). European man with himself. Notes about historico-cultural foundations and limits of personal self- consciousness. M. P. 404.

\section{About the Author}

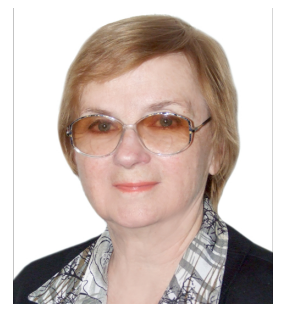

Kiyashchenko Larisa Pavlovna - Doctor of Philosophy, leading researcher of the sector of cross-disciplinary problems of scientific and technical development. Institute of philosophy of RAS. Russian Federation, 109240, Moscow, Goncharnaya St., 12, p. 1; e-mail: Larisakiyashchenko@gmail.com

Area of scientific interests: science philosophy, transdisciplinary paradigm, social epistemologiya, bioethics, mass culture

Author more than 90 works including two monographs "In search of Disappearing Concreteness (Sketches about Language Synergetics)", M., 2000; "Transdistsiplinary philosophy", M., 2009 (co-authorship). 